\title{
DIE VEREHRUNG DES HEILIGEN JOHANNES VON NEPOMUK IM ALTEN UNGARN
}

\author{
†Sándor BÁLINT \\ Lehrstuhl für Volkskunde \\ H-6722 Szeged, Egyetem u. 2, Ungarn
}

\begin{abstract}
Veneration of Saint John of Nepomuk in Hungary in the Past - Saint John of Nepomuk is the patron of Bohemia, one of the heavenly patrons of the Society of Jesus. He is also an important figure of Baroque popular religion in Eastern Europe and Hungary. His cult in Central Europe was spread by the Jesuits in the late 16th century. Because of his martyrdom (he was drowned) he is regarded as the patron saint of those who go on water, and of fishermen. In many places his statue stands beside rivers or streams, near bridges and ferries. Portrayals of him also appear on small devotional pictures. The article examines the cult of Saint John of Nepomuk in Hungary in the context of Central Europe. It presents in particular his veneration is the south of the Hungarian Great Plain and in Szeged, rites and customs linked to his feast (May 16th).

Keywords: cult of Saint John of Nepomuk, Baroque popular religion, Hungary, Central Europe
\end{abstract}

Johann von Nepomuk (16. Mai) ist der Patron Böhmens, einer der himmlischen Fürsprecher der Gesellschaft-Jesu, zugleich eine bevorrechtete heilige Gestalt der mitteleuropäischen barocken Frömmigkeit, der volkstümlichen Religiosität $(† 1383$ ?). Seine Legende ist in Mitteleuropa allbekannt.

Des heiligen Märtyrers Tod, den König Wenzeslaus so sehr verheimlichen wollte, offenbarte und verherrlichte Gott der Legende nach sofort mit Wunder: auf der Stelle umgab himmlische Helle den Leib des heiligen Märtyrers, und man sah am Wasser der ganzen Moldau eine zahllose Menge prächtig funkelnder brennender Kerzen schwimmen. Wo aber der Leib des heiligen Märtyrers an der Wasserfläche langsam dahinfloß, dort funkelte eine große Anzahl höher leichtender Fackeln, die in schöner Ordnung den heiligen Leib begleiteten und damit dem etwa ein Leichengepränge leisteten und die letzte Ehre erwiesen.

Darum preist ihn ein barockes Andachtsbild mit den Worten des 109. Psalmes: De torrente in via bibet, propterea exaltabit caput (Aus dem Bache trinkt er bei seinem Zug, Hoch kann er das Haupt drum erheben). ${ }^{1}$

Als im Laufe des Heiligsprechungsprozesses die Reste Johanns eröffnet wurden, fand man seine Zunge wie eine unaufschließbare Fundgrube der Beichtgeheimnisse, ohne je einem Verwesen und in frischem Zustand. In 1729 wurde er heiliggesprochen.

${ }^{1}$ Kleines Andachtsbild aus der Sammlung des Verfassers. Móra Ferenc Museum, Szeged 
Seine irdischen Reste wurden in der Prager Sankt Veit-Kathedrale zur Ruhestätte gebracht.

Was die wissenschaftliche Forschung betrifft, ist es nicht zu bezweifeln, daß ihn der König ermorden, in die Moldau ertränken ließ. Die Ursache aber ist bis heute ungeklärt. $\mathrm{Da} \beta$ er ein Märtyrer des Beichtsiegels sei, kam erst später nach der Volksüberlieferung zum Vorschein. Sein im königlichen Hof geführtes priesterliche Amt ist auch zweifelhaft. Dagegen ist es gewiß, daß er schon von seinen Zeitgenossen als ein Märtyrer Christi verehrt wurde. ${ }^{2}$ Unsere Aufgabe ist nicht die Zerlegung dieser Fragen. Man darf aber nicht vergessen, daß frühere Zeiten in Klärung der geschichtlichen Wahrheit auch die im Munde des Volkes fortlebende Überlieferung - ihrer Autoritätskraft wegen - oft als Quelle betrachteten. Allerdings fehlt eine monographische volkskundliche Aufarbeitung mitteleuropäischen Kultes des heiligen Johann von Nepomuk, obwohl man schon über mehrere wertvolle Teilabhandlungen verfügt. Die tschechischen Fachforschungen sind uns leider unbekannt.

Die Verehrung des heiligen Johann von Nepomuk wurde im Laufe des XVII. Jahrhunderts, nach dem Ablauf der Religionskriege in Böhmen von den Jesuiten vorbereitet. In der Gestalt Johannes vollte man einesteils das Mysterium des Priestertums, das Sakrament der Buße verklären, andernteils den mit dem Namen Huss, eines anderen ebenfalls Johann, bezeichneten häretischen Meinungen das Gegengewicht halten, in einer Frömmigkeit volkstümlicher Eigenart auflösen und die Achtung der Tradition und damit die dynastische Treue der Tschechen, ja sogar der Völker des ganzen Habsburg-Reiches erbauen.

Der Kult wurde also von den Jesuiten mit der unvergleichlichen Anschaulichkeit und den psychologischen Mitteln der barocken Seelsorge verbreitet. Nach der Auflösung der Gesellschaft, in der geistlichen Kühle des josefinistischen Rationalismus kommt er zwar herunter, in der volkstümlichen Frömmigkeit aber erlebt er sein vielleicht nur der Sankt Anna-Verehrung vergleichbares Nachblühen.

Was bedeutet Johann von Nepomuk dem Volk? Vorangehend sei uns erlaubt die Frage mit den Worten des barocken Hagiographen Andreas ILLYÉS zu beantworten: Er pflegt erfahrungsmäßig durch seine Fürbitte jenen Hilfe zu leisten, die in Gefahr einer Schmach, oder Verkürzung stehen. Und jenen, die sich davon fürchten, daß ihre geheimen Sünden und Missetaten offenbar werden. Viele seiner Verehrer haben dies erfahren. Sankt Johann hilft auch jenen, die aus gefährlicher Schamhaftigkeit sich schämen in der heiligen Beichte ihre eigenen Sünden wahrhaft zu bekennen.

Obendrein haben so die in Geburtswehen sich quälenden Weiber, wie die Wassersüchtigen und Schüttelfröstigen die Wirksamkeit seiner Flehen erfahren, sowie es die an seinem Grab angebrachten Gedenkgeschenke beweisen. Manche sind sogar bloß nur von seinem Grabstein abgeschabten Staub von vielen Krankheiten genesen... ${ }^{3}$

${ }^{2}$ Lexikon für Theologie und Kirche V. 519.; KRETZENBACHER 1961: 137., GUGITZ 1949. T. 266.; JUHÁSZ 1964.

${ }^{3}$ ILLYÉS 1743. 
Die Zunge Johannes blieb unversehrt. Dies ist die eine Quelle seiner Verehrung, etwa ein Symbol, da diese Zunge zu schweigen verstand. Kaum konnte die von vielen Richtungen sich angesammelte neuheimatliche Gesellschaft des XVIII. Jahrhunderts eine zeitgemäßere menschliche Aufgabe, christliche Pflicht haben, als mit der himmlischen Fürsprache Johannes den guten Ruf gegenseitig in Ehre zu halten, zugleich die Atmosphäre des gegenseitigen Vertrauens, eine Grundbedingung jedes gesellschaftlichen Lebens, sicher zu stellen. Ein ungarisches Gebet Um Bewahrung des guten Rufes und Namens fleht an Johannes Zunge also:

$\mathrm{O}$ grosser Fürsprecher und wirksamer Beschützer, glorreicher heiliger Johann von Nepomuk, dessen heilige Zunge vom allerhöchsten Herrgott, als ein Schutzmittel des Lobes seines heiligen Namens, des guten Rufes und Namens anderer mehr als dreihundert Jahre lang ohne jedes Verwesen gnädig bewahrt wurde. Mit einem frommen andächtigen Kuß verehre ich tausendmal diese heilige Zunge, Dich mit großer Demut bittend, daß du eine jede böse, mir feindselig gesinnte und ränkesüchtige Zunge zügeln wollest, nicht erlaubend, daß diese meiner oder meiner Nächsten Ehre schaden könnten. Sogleich aber lenke und leite auch meine Zunge im Reden und im Schweigen so, daß ich durch die Beiden meinem allerliebsten Gott hier auf Erden loben, dort aber in der seligen Ewigkeit ohne End preisen möge. Amen. ${ }^{4}$

Die Hauptflicht der zu Ehren des heiligen Johann entstandenen frommen Bruderschaften, die meistens unter Jesuitenleitung - nach unserem Wissen - in den Städten Temesvár (1724), ${ }^{5}$ Kalocsa (1750), ${ }^{6}$ Köszeg (Güns 1761), ${ }^{7}$ Györ (Raab, XVIII. Jhr. $)^{8}$ blühten, war eben die Achtung und Beschützung des guten Rufes der Menschen, Kampf und Gelöbnis gegen das Gerede und die Verleumdung. Aus seinem Leben, beziehungsweise aus seinem Martyrium ist es verständlich, daß neben diesen Bruderschaften hauptsächlich die Wasserfahrer ihn zum Patron wählten. Für die Allgemeinheit des Kultes ist es bezeichnend, daß dieser die Verehrung des heligen Nikolaus, bei den Wassermüllern aber die aus dem Mittelalter stammende, doch infolge der Reformation und der Türkenzeit verblasste Verehrung der heiligen Katharina in den Hintergrund stellte, fast auch vergessen machte.

Unter den „modernen“ Heiligen des XVIII. Jahrhunderts wurden die meisten neuen Kirchen, Kapellen, Altare zu seinen Ehren geweiht. Diese werden hier nicht aufgezählt. Diese Titel lassen die Neusiedlung der Nachtürkenzeit und die soziale Zusammensetzung unserer Heimat in bezeichnendem Lichte erscheinen. Der Kult erscheint zuerst in den städtischen Zentralen der Jesuiten: Buda (Ofen), Székesfehérvár (Stuhlweissenburg), Besztercebánya (Neusohl, Banská Bystrica), Temesvár, im Kreise der deutschen Bevölkerung, unter Wirkung der Zeitmode wurde er aber auch

${ }^{4}$ Aus einem Kleindruck, Nagyszombat, 1761.; Vgl. ANDREE 1904: 120

${ }^{5}$ BERECZ 1853: I. 192.

${ }^{6}$ Forma Saluberrimae Devotionis Virorum Bonum nomen diligentium Seu Confraternitas Sancti Joannis Nepomuceni In Metropolitana Colocensi Ecclesia Clero imprimis, ac Nobilitati proposita Anno Incarnationis Dominicae 1750. Budae, Typis Veronicae Nottesteinin, Vidae.

7 Vgl. Fußnote 6.

${ }^{8}$ BEDY 1939: 147. 
im Kreise unseres Volkes beliebt. Wie schon gesagt, seiner Volkstümlichkeit leistet Vorschub seine dynastische Begeisterung.

Neben der heiligen Dreifaltigkeit und der Unbefleckten Empfängnis ist das Standbild des heiligen Johannes mit seiner artistisch-sakralen Atmosphäre ein höchst charakteristisches Raumbildungselement des ungarischen, beziehungsweise mitteleuropäischen barocken Stadtbildes. Es ist aber auch in den Frontnischen der Häuser jener Zeit, an den Straßen, neben Brunnen und Brücken, selbst auf den Brücken, am Fuße der Fähren, am Rande wasserdurchdrungener Stellen zu finden. Die Standbildkomposition (1744) am Markt zu Magyaróvár (Ungarisch-Altenburg) ist wahrscheinlich das höchst monumentale heimatliche Johannes-Denkmal, mit Reliefszenen: er hört die Beichte der Königin, es wird ihm vom König die Bischofswürde angetragen, er wird in die Moldau ertränkt. Es ist aber gleichzeitig auch eine Pestsäule. Man sieht am Werk die Statuen des Anton, Sebastian, Karl, auch das Relief der Rosalia, welches mit seinem dreieckigen Grundriß auch noch an die heilige Dreifaltigkeit erinnert.

Das erste Szegediner Standbild Johannes wurde noch im XVIII. Jahrhundert, gleich nach der Heiligsprechung vor der Festung, bei der Schiffbrücke an der Tisza (Theiß), bei dem Vorfahr der jetzigen Verkehrsbrücke aufgestellt. István P. KISs, Franziskaner aus der Unterstadt ist in seinem Heiligenlandes-Reisetagebuch ${ }^{9}$ dessen folgend eingedenkt: Sollte ich mich in Szeged am Wasser der Theiß auf den Weg machen, so könnte ich ohne festen Boden zu berühren auch Alexandrien erreichen immer wasserwärts. Hieraus aber ganz Amerika, Afrika, sogar Indien, und könnte meine Reise so richten, daß ich binnen vier Jahren das ganze Erdenrund umgehen könnte aus Szeged überall wasserwärts und wieder in Szeged springete ich heraus bei dem Standbild des heiligen Johannes Nepomucenos unter der Festung, oder wo es mir gefällig wäre, wenn auch gleich bei der Boszorkánysziget (Hexen-Insel). Wer dies nicht glaubt, probiere es selbst und wie ich es schreibe, so wird jener es erfahren.

In der Oberstadt, im Herzen des Szegediner Wasserlebens, in der Nachbarschaft der am Ufer befindlichen Salzscheuern stand seine mächtige Marktbildsäule, welche von der Überschwämmung (1879) zusammengestürzt wurde. Am Johannestag wurde sie mit Blumen aufgeschmückt und ihre herzförmige Lampe angezündet. An diesem Platz war der Stand der Fuhrleute und so war Johann gleichsam auch der Schutzheilige der Fuhrleute, die sich in die Schenke an der Ecke hineinsetzten, ihre Ochsen und Wägen auf sich selbst ließen und ungarisch sangen:

Kleiner Fuhrmann, grosser Fuhrmann

Sucht immer die Schenke.

Solange er sich aufhält in der Schenke,

Gibt Sankt Johann acht auf seine Ochsen.

${ }^{9}$ P. KISS 1958: 111. 
Es kam auch vor, daß das in den Fuhrmann verliebte Mädchen von den Blumenkränzen, welche die Bildsäule des Heiligen bedeckten, heimnahmen um zu bezaubern.

Die Bildsäule wurde in den sechziger Jahren des vorigen Jahrhunderts erneuert, da eigentümlicherweise ein ganz Szeged zerstörender Hagel die Oberstadt verschonte. Dies wurde der Fürsprache Johannes zugeschrieben. Nach dem Hochwasser (1879) wurde sie abgetragen, weil durch den Platz eine neue Gasse eröffnet wurde. Dies bedauerten die Wassergänger und die Fuhrleute eine lange Zeit.

Von seinen an den Brücken erscheinenden Standbildern sind die höchst charakteristischen: Vác (Waitzen, Gombáspatak, 1753), Domherr Franz Würth errichtete es. Dessen Kronostichon lautet: PATRONE IN ANXIO VITAE STATU FERMAE PERICULO DEVOTIS TUIS AUXILIARE (1761). ${ }^{10}$ Seine anderen ähnlichen Standbilder sind: Pozsony (Pressburg, Bratislava, bei der Brücke des Sankt MichaelTores in der Gesellschaft des Erzengels, XVIII. Jahrh., Pápa (1753), Cikó (XVIII. Jahrh.), Vassurány (XVIII. Jahrh.), Tata (Totis, 1770, im Jahre 1945 zugrunde gegangen), Diszel (XVIII. Jahrh.), Örvényes (1800), Bátaszék. ${ }^{11}$

Mühlen werden auch dem Schutz Johannes empfohlen. Eine solche ist die kunstvolle Nepomucenusmühle in Tata (1758).

Die provinziale Vertraulichkeit des ungarischen Bauernbarocks führt das am Rande eines mächtigen Grabens stehende Standbild in Fegyvernek an, unter einem an die barocken Ideenwelt der heiligen Dreifaltigkeit erinnernden, auf drei Füßen stehenden Dach: der Heilige empfiehlt seine Zunge der Jungfrau Maria (1775). Gleicherweise ist ein Dreieck die Grundansicht der am Ufer des Gyöngyöscher Nagypatak (= großer Bach) stehenden Nepomuk-Kapelle, die von den Jesuiten gebaut wurde (1736). ${ }^{12}$

Ein Meisterwerk der Bauernbauführung sakraler Tendenz ist das Standbild der Gemeinde Apátfalva in der Nähe des Maros Flußes. Ober ihm ist ein von vier weiß getünchten, dielenartig ausgebildeten Säulen getragenes Rohr-, neuerdings Schindeldach. Eine wohlhabende Bäuerin: Apollonia Mészáros ließ es aufrichten (1824). ${ }^{13}$ Dem ähnlich war auch das Standbild in Tápé, statt Mauer umringte es aber ein Gitterzaun.

Am Rand des Dorfes in ergreifend schöner Anlage steht das Johannes-Standbild in Dusnok: vier mächtige Pappeln umringen es.

Im Standbild am Kirchenplatz des wasserarmen Jászladány wird der Beschützer des guten Rufes gefeiert:

\footnotetext{
${ }^{10}$ BÓNISNÉ 1935: 71.

${ }^{11}$ AgGHÁZY 1959: II. 57, 302.

12 KOZÁK 1959: 142.

${ }^{13}$ SZENTKLÁRAY 1898: 228.
} 


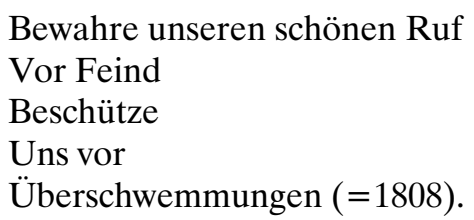

Sollte man genau in Betracht nehmen, könnte man gewiß noch viele charakteristische, in die heimatliche Landschaft gewurzelte Denkmale Johannes kennen lernen. Solche sind die kunstvollen Standbilder in Kemence (1778) ${ }^{14}$ und Kiskundorozsma.

An die Nepomuk-Standbilder knüpfen sich hier und dort auch spaßige Volksüberlieferungen.

In Tápé gibt man den Unbewanderten damit zu denken, wenn ihr Johann die Rufglocke zur Weihnachtsmesse hört, geht er hinunter zur Theiß trinken. Nachher nimmt er seinen Platz wieder auf ein Jahr in Besitz.

Vom Standbild in Bakonybél wird auch gesprochen, daß er seine Kappe herunternimmt, wenn er die Mittagsglocke läuten hört. Man sagt, daß ein sanftmütiger Landsmann aus Herend auch zur Mittagszeit auf ihn paßte, aber vergebens. Bei der Abtei wurde der Heilige von ihm auch angeklagt. Man versuchte ihn damit auszusöhnen, dass er nun diesmal nicht hörte, aber vielleicht - morgen. ${ }^{15}$

Die gutgelaunten Burschen in Szentmihálytelek noch in der ersten Hälfte des Jahrhunderts pflegten Johann zu seinem Namenstag mit Musik zu begrüssen, ebenso auch die dort vorüberziehenden Hochzeitsgäste.

In der Gemeinde Igmánd ging der Zigeuner eines Morgens eben aus der Hochzeit nach Hause. Sein Weg führte über die Brücke des Teiches am Ende des Dorfes. Johann Vetter, soll ich ihnen ein Morgenstück spielen? - frug der Zigeuner berauschten Hauptes das Standbild Sankt Johannes auf der Brücke und keine Antwort erwartend fing er an ein Lied auf seiner Geige zu spielen. ${ }^{16}$

$\mathrm{Zu}$ diesen Standbildern ging am Fest und dessen Oktav bis zu neuester Zeit eine Prozession aus der Kirche. Wie man sagte: Der Sankt Johann wurde gegangen. Hier wurde gesungen und die Litanei des Heiligen verrichtet, dann aber das Standbild bekränzt. In einem Dorfe des Komitates Heves legte ein kleines Mädchen zur Kirchweih' einen Kranz auf das Standbild Johannes. Der Kranz blühte - nach örtlicher Sage - auf's Jahr wieder auf. ${ }^{17}$

Vom Feiern der ehemaligen edlen, hochwohlgeborenen Müllerzunft von Vác weiß man nur soviel, daß im vergangenen Jahrhundert für das Standbild des Heiligen aus Stein gebildet, welches bei dem Hafen herumsteht, von den Meistern dicke

\footnotetext{
${ }^{14}$ Magyarország Múemléki Topográfiája V. I. 447.

15 MALONYAY 1912: 11.

16 Vom Schriftsteller Mór Jókai zitiert: DOMOKos 1961: 257.

${ }^{17}$ Ethnographia, 1907: 151.
} 
Blumenkränze geflochten wurden, in den glänzend beleuchteten Mühlen aber spielte die Musik. ${ }^{18}$

Johann war der Schutzheilige der Pestbuda-er Schiffer, Brückenzöllner und Wassermüller. Von den letzteren wurde im vorigen Jahrhundert der Tag so gefeiert, dass am Vorabend die Donaumühlen beleuchtet und dekoriert wurden, weiterhin wurden unter Musikbegleitung und Mörsergeschmetter einige beleuchteten Kähne vom Stapel gelassen. Natürlich hatte die Feierlichkeit an beiden Ufern viele $\mathrm{Zu}$ schauer. Das in der Mitte der Schiffbrücke stehende Sankt Johannes-Bild pflegte man mit grünen Zweigen und Blumen aufzuschmücken. Vor dem auch mit Lampen beleuchteten Bild verrichteten viele ihre Andacht. An den Ufern ging bis Mitternacht die Schießerei und das Loslassen der Raketen. ${ }^{19}$

In der Stadt Baja blühte fast bis an unseren Tagen das Hänschen-Lassen (Jánoska-eresztés). ${ }^{20}$ Anfangs feierten dies nur die Wassermüller, eiligst wurde es aber von der ganzen dortigen Wassergesellschaft in Evidenz gehalten.

Von Johann benannte man einen extra Stadtteil, wo eine Kapelle zu seinen Ehren gebaut wurde. Das Fest stand ursprünglich mit dem Kirchweihtag in Zusammenhang. Nach dem Litanei-Segen - als es schon Abend geworden ist - brachten die Wassermüller die Holzstatue des Heiligen aus der Kapelle heraus und trugen sie mit grünen Zweigen, Kirchenfahnen, Lampions, Fackeln, brennenden Kerzen auf eine Plätte, später aber auf eine Fähre und stellten sie dort auf ein dekoriertes Podium. Hinter ihr nahmen die Müllermeister Platz, später die Abkömmlinge der alten Müllerfamilien, bzw. die Vertreter der städtischen und kirchlichen Leitung.

Vor der Plätte rückte das Leitboot vor. Daraus wurden die scherzhaft „,herkentyü“ genannten Raketen in die Höhe geschossen. Die Plätte mit der Statue wurde von den mit dem Rudern beauftragten Müllerburschen gelenkt. Nachher folgten in schöner Ordnung beleuchtete und aufgeschmückte Plätten und Kähne.

Richtig behauptet Imre DANKÓ, daß das Hänschen-Lassen eigentlich ein Wasserumgang war, welcher aus der Kapelle aus der Sugovica (Donau-Arm) entlang ging und unter dem Hauptplatz endete. Hier wartete eine große Menschenmenge. Die Musik fing an zu spielen. Es begann die Unterhaltung. Es kochte die Fischbrühe (Halpaprikás), mit welcher die werteren Teilnehmer bewirtet wurden.

Nach der Feierlichkeit wurde das Hänschen, das heißt die Statue, lautlos in die Kapelle zurückgetragen. Hier folgte noch eine siebentägige Andacht.

Bis heute wird noch oft davon gesprochen, daß die Müllerburschen, als sie einmal mit der Statute in die Kapelle zurück trachteten, auf der Pandur-Insel um einen Trunk Weins ausstiegen. Nur am Ende hatte es sich herausgestellt, dass sie kein Geld bei sich haben. Sie waren gezwungen die Statue zum Pfand zu geben. Am nächsten Tag wurde sie von den Müllermeistern ausgelöst. Ein andermal, ein wenig schon betrunken, ließen sie die Statue in das Wasser fallen und konnten sie kaum herausfangen. Manchmal wurde die Statue in der Donau auch gebadet. Dies ge-

\footnotetext{
18 TRAGOR 1923: 161.

19 ZoLTÁN, József 61.

${ }^{20}$ DANKÓ 1958: 145.
} 
schah gewiß zu trockenen Zeiten. Am Johannesabend wurde die Mohácser Fähre mit Maibaumästen aufgeschmückt. Die Statue des Heiligen wurde in die Mitte gestellt, mit Blumen geschmückt und mit Lampions beleuchtet. Die Fähre zog ein Schiff bis zum Denkmal der Schlacht bei Mohács (1526) hinauf. Von dort ließ sie sich schön langsam hinunter bis zum Hafen. Am Schiff musizierten die Bläser. Da war die ganze Stadt draußen am Ufer der Donau.

Auch das Volk Ercsi neben der Donau ließ früher auf kleine Flöße geklebte, brennende, leuchtende Kerzen am Festabend auf das Wasser. Ähnliche Tradition lebte auch in Apatin. ${ }^{21}$

Das Wasserfest Dunaharaszti wollte eigentlich auch die Legende, das nächtliche Funkeln der Moldau anführen. Am Abend des Festes gingen die Gläubigen zur Donau hinunter, wo auf einem quadratförmigen Brett eine Kerze angezündet, dann aber auf das Wasser gelassen wurde. Unterdies wurde gesungen, die Litanei des Heiligen, eventuell der Rosenkranz gebetet solange, bis das Licht der Kerze ausgegangen, oder im Röhricht verschwunden ist.

$\mathrm{Zu}$ dem einstigen Johannes-Standbild am Ufer der Donau zu Gyór (Raab) zogen die Angehörigen der hiesigen Wasserleute besonders dann hinaus um zu beten, wenn am Fluß ein Sturm brauste und die Ihrigen dort rangen.

Im wasserumringten Györ blühte übrigens der Kult immer. Bei der alten RábcaBrücke ist mit dem Mauthaus zusammengebaut eine Kapelle zu Ehren Johannes. Die Kapelle, deren Verwalter der jeweilige Zöllner war, steht auch jetzt und wird während der Oktave bis heute von Vielen aufgesucht. ${ }^{22}$

Die Székesfehérvárer (Stuhlweissenburg) Kirche der Jesuiten ist wahrscheinlich die schönste einheimische Johanneskirche (1751). Ursprünglich wurde sie von der deutschen Bürgerschaft als die ihrige betrachtet. Sollte der Weissenburger die Absicht haben hierher zu gehen, so sagt er auch noch heutzutage: Ich gehe zu den Deutschen.

Über dem Tor ist das Verdienst Johannes in ein Psalmzitat (Ps. 31,3) zusammengefaßt: QUONIAM TACUI (=Weil ich schwieg).

Das Hochaltarbild schildert die Verherrlichung Johannes. Es ist ein Werk Sambachs, eigentlich eine mächtige Freske. Am Fuße des Bildes stützt sich ein verlumpter Junge mit der beißenden Schlange des Gewissens an eine Säule. Er hofft die Vergebung. An der Stiege grübelt ein bärtiger Mann in sich. Nach der örtlichen Überlieferung soll es Lorenz Vánossy sein, ein königlicher Dreißigstler, der auf illegitimer Weise ein mächtiges Vermögen zusammenscharrte. Vielleicht opferte von diesem sein Sohn, ein Jesuit, der auf der Freske ebenfalls zu sehen ist, hunderttausend Gulden für den Kirchenbau zur Söhnung der Sünden seines Vaters.

Die Familie Koháry ließ die Kapelle in Hontszentantal (Sväty Antol) bauen und darin den Johannes-Altar, ein anderes, Johann gewidmetes Meisterwerk Altungarns. Auf der Freske an der Vorderwand des Kastells erscheint der Heilige als der Beschützer der adeligen Familie. 
Die Aufschrift des Altarbildes der Minoritenkirche zu Eger lautet: BEATUS, QUI IN LINGUA SUA NON EST LAPSUS (Eccl. 25,7) (Glücklich, wer mit der Zunge sich nicht verfehlt). Das Bild wird von den Statuen der beiden Johannes: des Täufers und des Evangelisten in die Mitte genommen. Am Altar Búcsúszentlászló schließt sich noch der heilige Johann Capistranus ihnen an.

Es zeigt auf die sakrale Zeitmode hin, daß die Kamaldulenser Eremiten zu Majk auch ihn zum Schutzpatron wählten (1731).

Sehr schön ist die epitaphienartige Johannes-Komposition der Seminarkirche Unserer Lieben Frau vom Berge Karmel zu Székesfehérvár und die der Kirche Szentsimon. Die Letztere schließt die drei charakteristischen Kultenströmungen des Jahrhunderts in ein Werk: die Unbefleckte Empfängnis, das Familiengnadenbild der Habsburg-Dynastie (Maria mit geneigtem Haupte) und den heiligen Johannes von Nepomuk.

Das in der Ofner Garnisonskirche gestandene, jetzt im Museum der Schönen Künste sichtliche ist vielleicht das erste einheimische, aus ein Gelöbnis errichtete Altarbild Johannes. Dessen Widmung lautet folgend: DIVO JOANNI NEPOMUCENO SACERDOTI ILLIBATO DOCTORI EXIMIO JURATO CHRISTI SECRETARIO MARTYRI OB INVIOLATUM CONFESSIONIS INVICTO PATRONO SIBI SPECIALITER VENERANDO OBTULIT PERPETUO DEVOTUS CLIENS ANTONIUS NICOLAUS JOHANNES HANTSCHL (Dem seligen Johann von Nepomuk, dem unbefleckten Priester, dem außerordentlichen Lehrer, dem vereidigten Märtyrer-Sekretär Christi, dem des unversehrten Beichtsiegels wegen Unbesiegten, dem seinerseits in besonderer Weise verehrenden Patron widmete es der auf Immer treu ergebene Schützling Anton Nikolaus Johann Hantschl). ${ }^{23}$

Johann ist ein Märtyrer des Beichtsiegels. Es ist verständlich, dass seine Statue, sein Bild oft auch auf die Vorderseite des Beichtstuhles kommt. So in den Kirchen Nagymányok und Sárkeresztúr. Bezeichnend ist die Psalmparaphrase der Bildes der Hétkápolna (Siebenkapellen) zu Vác: POSUI DOMINE CUSTODIAM ORI MEO ET SACRAMENTALE ARCANUM NON PANDI (Ps. 38,2), das heißt: Herr, ich verwahrte meinen Mund mit einem Zaun und das sakramentale Geheimnis öffnete ich nicht. Die Anschrift eines barocken Andachtsbildchens Johannes lautet: S. JOANNES NEPOM. MARTYR PATRONUS IN OMNI NECESSITATE (Der heilige Johann von Nepomuk Märtyrer ist Helfer in jeder Not). Daraus ist es verständlich, daß zur spätbarocken Blütezeit seines Kultes nicht nur seine Statue, sondern auch das an ihn gerichtete Bittgebet an die Vorderwand der Häuser kam. So in Buda (Ofen): ADSIS AUXILIUM FLAGITO TER SANCTE JOANNES ATQUE FAVORE TUO PROTEGE CUNCTA DOMUS (1725, = Inständig flehe ich, sei unsere Hilfe, dreimal heiliger Johann, und mit deiner Gunst schirme alle Häuser). ${ }^{24}$

Auffallend ist es, daß - nach unserem Wissen - Johann aus der Reihe der Helden der ungarländischen barocken Schuldramen fast gänzlich fehlt. Wir haben 
nur von einer, zu seinen Ehren komponierten Oper ungarisch-lateinischen Textes Kenntnis, welche zu Györ (Raab) in 1749 gewiß auch aufgeführt wurde. Deren ungarischer Titel lautet: Megsértödött ártatlanság, a kiért Istennek ereje bosszut állt (Die beleidigte Unschuld, für welche die Kraft Gottes Rache nahm). ${ }^{25}$

Sehr bezeichnend ist die Votivpilgerfahrt des Szegediner Franziskanerbrunders EFREM KoCsis (1868). ${ }^{26}$ Als er das vorige Jahr im Heiligen Land war, entstand bei seiner Schiffreise ein mächtiger Meeressturm. In Todesangst dünkte ihn, der heilige Johann von Nepomuk sei ihm erschienen. Er winkte auch, daß er sich nicht fürchte. Da gelobte Bruder Efrem die Pilgerfahrt nach Prag. In seinem Entschluß wurde er auch dadurch verstärkt, daß er daran dachte, wie er in Kindheit an dem SanktJohann-Gang teilnahm, das heißt: in der Oktave des Festes sein Standbild mit Teilnahme an der Prozession verehrte. Unterwegs traf er auf einen Sozius: den Maurerburschen Antal Lugosi.

Das in schmackhaftem Ungarisch geschriebene Tagebuch des Bruders sollte man im ganzen anführen. Man begnüge sich hier jedoch nur mit einem kleinen Teil davon: Wir Ungarn waren nur zu zweien als Pilger in der Prager Kirche, ich und mein Kamerad. Neben dem silbernen Sarg des heiligen Johann von Nepomuk stehend und den Wallfahrtsgesang horchend habe ich gedacht, daß es doch auch uns gebühre in unserer lieben ungarischen Heimatssprache ein Wallfahrtslied zu singen. Wir können doch auch ein sehr-sehr ergreifend schönes Lied zu Ehren des heiligen Johann von Nepomuk. Und unsere Stimme wird auch vollauf ausreichen, obwohl wir Ungarn nur zu zweien sind... Als ich dies so in meinem Kopf rund erdachte, geriet ich derart in Eifer, daß ich mit Hilfe meines Maurergesellen fol-gendes schöne Lied auswendig zu singen anfing:

\section{Lobet, ehret ihr Christen}

Den heiligen Johann von Nepomuk, Ihr wahren guten Gläubigen.

Den treuen Diener Gottes,

Den lieben Märtyrer Christi,

Der für Ihn den schrecklichen

Tod verschmähte.

Du bist der Morgenstern der Stadt Prag,

Du bist ihre Perle, teurer Schatz, schöne Krone.

Zierde deiner Nation, Glanz Böhmens,

Ja sogar die Pracht der ganzen Welt.

Während der Klang unseres ungarischen Liedes das Innere der schön großen Kirche durchdrang, merkten wir, daß das schon heimströmende Volk sich umkehrte und uns andächtig anstaunend bis zu Ende anhörte. Die Sprache der Frömmigkeit 
versteht doch ein jedes Herz. Sie scheinen unsere gute Absicht auch verstanden zu haben. Denn wir waren nur unsere zwei, die wir sangen, oder eben deswegen umringte uns das Volk, sogar auch vom Herrenstand, unter andächtigen Tränen. O mein lieber Gott, dachte ich in mir, wie wenig bedarf das Menschenherz um glücklich zu sein.

Bruder Efrem erzählt in seinen Erinnerungen noch eine Ergebenheit: wie Graf Leo Thun sich ihrer annahm und sie zu seinem Tisch setzte, dessen Sohn - dem Vernehmen des Bruders nach - auf die himmlische Fürsprache Johannes zu der Zeit geheilt ist.

Von einer anderen charakteristischen, ja sogar komischen Szegediner Offenbarung der Johannes-Verehrung gibt der Szegediner Fischermeister Johann BITÓ Rechenschaft. In seiner Autobiographie ${ }^{27}$ erzählt er, daß sein Fischmesser „ein von dem alten Sziráki - vom dem der berühmte ungarische Schriftsteller Kálmán Mikszáth eine Novelle schrieb - um 16 Gulden verfertigtes Meisterstück sei. An der einen Seite war der heilige Johann von Nepomuk, der Schutzheilige der Gewässer eingraviert, an der anderen Seite ein Karpfen und mein Monogramm. Der Graveur Statner gravierte es ein um 4 Gulden. Von diesem Schnappmesser hätte ich mich nicht um die Welt getrennt, wenn ich mich auf dem Weg machte, denn es war geweiht. Der Herr Pfarrer der Oberstadt, Jazint Orbán weihte es und ich hielt so fest an diesem Schnappmesser, wie an einem Talisman. Wenn mir ein Übel drohte, griff ich nur in meine Tasche, packte es an und sogleich fühlte ich, dass meiner Seele leichter geworden ist, mein Schutzheilige ist mit mir an das Schnappmesser graviert." Diesem Schnappmesser forschte man im Kreise der Familie nach, leider, vergebens.

Der regionalen Zusammengehörigkeit wegen wird noch erwähnt, daß die mit der Tápé'schen Fähre ziehenden Wallfahrer aus der Gegend Szeged da die Litanei des heiligen Johann von Nepomuk zu verrichten pflegen.

Die Johann preisende Menge der einheimischen Andachtsbildchen, kleine Drucksachen, Volksschriften ist fast unübersehbar. Nennenswert ist die vom Jászárokszálláser Volksdichter Ludwig Varga um 1900 in Verse gefaßte Biographie: Nepomuki szent János, vagy a gyónás szentségének vértanúja. (= Heiliger Johann von Nepomuk, oder der Märtyrer des Sakramentes der Beichte). Auffallend folgt sie die Darstellung des Andreas ILLYÉs. ${ }^{28}$

\section{LITERATUR}

AGGHÁZY, Mária

1959: A barokk szobrászat Magyarországon (Bildhauerei im Barock in Ungarn). I-III. Budapest. ANDREE, Richard

1904: Votive und Weihegaben des katholischen Volkes in Süddeutschland. Braunschweig. BEDY, Vince

1939: Győr katolikus vallásos életének múltja (Die Vergangenheit des katholischen Lebens in Győr/ Raab). Győr.

27 BITÓ 1930: 109.

${ }^{28}$ VARGA o. J. 


\section{BERECZ, Imre}

1853: Nepomuki Szent János társulatának rommaradványai Temesvárott (Ruinenreste der Confraternitas von Hl. Johannes von Nepomuk). Családi Lapok, I.

BITÓ, János

1930: Az én kiskirályságom (Mein kleines Königreich). Szeged.

BÓNISNÉ WALLON, Emma

1935: Vác múvészete a XVIII. században (Die Art in Vac/Waitzen im 18. Jahrhundert). Budapest. DANKÓ, Imre

1958: A bajai Jánoska-eresztés (Hänschen-lassen in der Stadt Baja). Ethnographia LXIX

DOMOKOs, Pál Péter

1961: Hajnal, hajnalnóta, hajnalozás (Das Morgenlied). Ethnographia LXXII.

Fr. EFRÉM

1888: Fr. Efrém zarándoknaplója (Das Tagebuch des Pilgers Fr. Efrém). Közli (Veröffentlicht von)

GRÜNN, Helene

1968: Volkskunde der heimatvertriebenen Deutschen im Raum von Linz. Veröffentlichungen des Österreichischen Museums für Volkskunde, XIII. Wien.

GuGITZ, Gustav

1949: Das Jahr und seine Feste im Volksbrauch Österreichs. I. Wien.

ILLYÉS, András

1743: Keresztyéni életnek példája avagy tüköre, az az: a szentek élete, mellyet réges tudós és nevezetes olasz auctorok könyveiből, kiváltképpen való szorgalmatossággal, olasz nyelven megmagyarázott Magyarországban és rendesen öt részre osztott ... Most pedig meg-jobbítással negyedszer is magyarul ki-nyomtattatott és meg-többített Nepomuki Szent János életével. (Beispiel oder Spiegel des christlichen Lebens ...) Nagy-Szombat.

JUHÁsZ, Koloman

1964: Der heilige Johannes Nepomuk als Schutzpatron des Banates. Österreichische Zeitschrift für Volkskunde.

P. KISS, István

1958: Jeruzsálemi utazás (Pilgerfahrt nach Jerusalem). A bevezetést és a jegyzeteket írta (Einführung und Anmerkungen von) PÁszTOR, Lajos. Róma.

KozÁK, Károly

1959: Háromszög alaprajzú, XVIII. századi épületek Magyarországon (Dreieckige Gebäude in Ungarn im 18. Jahrhundert). Múemlékvédelem.

KRETZENBACHER, Leopold

1961: Heimat im Volksbarock. Kulturhistorische Wanderungen in den Südostalpenländern. Klagenfurt.

1962: Lichterschwemmen als Kulturbrauch. Zbornik za narodni život i običaje.

Lexikon für Theologie und Kirche I-X.

Magyarország Múemléki Topográfiája (Denkmaltopographie Ungarns) IV. Budapest múemlékei. Budapest, 1958.

MALONYAI, Dezsô

1912: A dunántúli magyar nép múvészete (Art des ungarischen Volkes in Transdanubien). Budapest.

SCHMIDT, Leopold

1937: Volksschauspiele von heiligen Johann von Nepomuk. Volk und Volkstum II.

1960: Johannesandachten und Nepomuklieder in Niederösterreich und im Burgenland. Jahrbuch des österreichischen Volksliedwerkes IX.

SZENTKLÁRAY, Jenő

1898: A Csanád-egyházmegyei plébániák története (Geschichte der Pfarreien in der Diözese Tschanad). Temesvár.

TAKÁCS, József

1937: A jezsuita iskoladráma 1581-1773 (Das Schuldrama der Jesuiten 1581-1773). Budapest.

TRAGOR, Ignác

1923: Váci érdekességek (Merkwürdigkeiten aus Vác/Waitzen). Vác.

VARGA, Lajos

(o. J.): Szentek élete és csodatetteinek leírása. I. (Leben der Heiligen und die Beschreibung ihrer Wunder) Eger. 